\title{
QUALITY EVALUATION OF BLUEBERRY FROM LOWER VISTULA REGION
}

\author{
Tomasz Hebda, Beata Brzychczyk, Norbert Pedryc, Slawomir Francik \\ University of Agriculture in Krakow, Poland \\ tomasz.hebda@ur.krakow.pl, beata.brzychczyk@ur.krakow.pl, \\ norbert.pedryc@ur.krakow.pl, slawomir.francik@urk.edu.pl
}

\begin{abstract}
Blueberry fruits have been a valuable subject in human nutrition for many decades. They are known all over the world, not only because of the taste, but also because of their numerous health and nutritional values. They show properties that are of great importance in the prevention of civilization diseases. They are ideal for direct consumption, as well as for preserves and frozen foods. The purpose of the work was to determine the quality of blueberry fruit after harvest and after storage. Average size, fruit weight, time influence on the sugar content in fruit and changes in firmness of berries were determined. The research concerned the cultivars: "Aurora", "Bluecrop", "Brigitta", "Chandler", "Darrow", "Duke", "Eliot" and "Liberty". The obtained results allow to conclude that the fruits of the largest mass and size are present in the Darrow variant and the lowest in the Liberty cultivar. "Chandler" has the highest hardness, thanks to which the fruits are less susceptible to damage. The smallest hardness was for "Duke". After storage, the firmness of all cultivars increased with the exception of the "Darrow" cultivar, this was the result of transpiration. The "Liberty" cultivar after 21 days from harvest had the highest hardness, and the "Brigitta" cultivar had the smallest. The "Darrow" cultivar is the only one to reduce hardness after storage, which indicates less resistance to storage. The following conclusions were made in the work: lowering the storage temperature to $3{ }^{\circ} \mathrm{C}$ in a statistically significant way slows the biological processes leading to maturation and overgrowth of bilberry fruits; along with the increase in the storage period, the weight and size of the fruit of all the cultivars studied decrease, and the characteristic creases appear on the fruit; as time goes on, the sugar content of the tested cultivars increases as a result of fruit ripening.
\end{abstract}

Keywords: blueberry, cultivars, quality.

\section{Introduction}

For many years there has been an increasing demand for blueberry fruits, as evidenced by the growing number of crops of this plant annually and larger crops. It is estimated that global production of blueberries can reach up to 900,000 tonnes in 2019, from 650,000 tonnes in 2017.

Small blue blueberry fruits, of the genus Vaccinium L., have been a valuable position in human nutrition for many decades. They are known all over the world, not only because of their taste, but also because of their numerous health and nutritional values [1;2]. Blueberry fruits have a high content of phenolic compounds with a wide range of biochemical activities. They show properties that are of great importance in the prevention of civilization diseases. They act as antioxidants, anti-mutagens, protect the cardiovascular system, have antidiabetic effects, have a positive effect on the eyesight and inhibit the formation of tumors [3-5].

Blueberries have a short shelf life. Therefore, it is a big problem to provide consumers with high quality fruit for direct consumption, not only after harvesting, but also in autumn or winter. Fruit quality - evaluated by the color, size, shape, texture and firmness as well as the taste and nutritional value - depends on many factors [6]. The most important ones include varietal features, the date and method of harvesting, post-harvest treatment as well as the method and amount of storage temperature $[1 ; 7 ; 8]$. It was found that the optimal storage time, at $0{ }^{\circ} \mathrm{C}$, should be between 14 and 20 days [9]. Other studies concern storage at 4 and $15^{\circ} \mathrm{C}$ (Matiacevic et al. [10]).

The purpose of the work was to determine the quality of fruit of eight selected blueberry cultivars at the time of harvest and after storage. The study determined the average size, fruit weight, time influence on the sugar content in individual blueberry cultivars and changes in berry firmness resulting from the passage of time.

\section{Materials and methods}

Blueberry fruit intended for the research was obtained from an agricultural holding located in Szczucin, Małopolska province. The area of the farm is 11 ha. The shrubs were planted on 5th and 6th grade podzolic soil in 1997. The leading variant of blueberry cultivated on the plantation is Bluecrop, occupying $60 \%$ of the farm area. Blueberry fruits of the following cultivars were selected for the research: "Aurora", "Bluecrop", "Brigitta", "Chandler", "Darrow", "Duke", "Eliot" and "Liberty". 
Hand-picked fruit were divided in two parts, one for the study and the other for storage. The berries were stored in packages of the capacity of $125 \mathrm{~g}$. The container and lid were made of PET. The bottom of the container and the lid were perforated for faster cooling. The storage period was 21 days. Temperature for storage was $3{ }^{\circ} \mathrm{C}$, whereas relative humidity $85 \%$.

Of each cultivar, 50 individual berries were randomly selected for study.

The measurement of the height and diameter of blueberry fruit was made using the LIMIT electronic caliper with the accuracy of measurements $( \pm 0.01 \mathrm{~mm})$. The weight of a single fruit was determined using the RADWAG WSP 510/C/1 electronic laboratory scales, with a measurement accuracy of up to $0.001 \mathrm{~g}$. The study of blueberry fruit firmness was carried out using a MTS Insight 2 testing machine connected to a computer through the TestWorks ${ }^{\mathrm{TM}}$ computer program. The test consisted in measuring the value of force and deformation in the area of destructive deformations. Two metal plates, parallel to each other, were used for the tests. Blueberry fruit was placed on a fixed bottom plate. After starting the test, the upper plate moved down at a constant speed of $10 \mathrm{~mm} \cdot \mathrm{min}^{-1}$ until the fruit was crushed. The sugar content in the fruit was determined using the Portable Refractometer RHB-32 optical refractometer, equipped with a scale of $0-32^{\circ}$ Brix and a resolution of $0.1^{\circ}$ Brix $\left({ }^{\circ} \mathrm{Bx}\right)$.

\section{Results and discussion}

The conversion of the measurement data and their statistical analysis were carried out using Excel and Statistica. The obtained test results are presented in diagrams as averages of the measurements for each cultivar.

The graph (Fig. 1) presents the results of the study of the weight of blueberry fruit for individual cultivars, fresh and after the storage period. The highest average weight was recorded for the "Darrow" cultivar (3.41 g), slightly smaller for the "Chandler" cultivar (3.10 g). A similar mass of fruit was observed in the "Brigitta" and "Bluecrop" cultivars $-1.8 \mathrm{~g}$ and $1.86 \mathrm{~g}$, respectively. The research carried out showed that the smallest mean weight among the tested cultivars is found with the Liberty cultivar, and it amounts to $1.52 \mathrm{~g}$. After the storage period, the weight loss was recorded for each of the tested cultivars. The largest weight loss occurred in the "Chandler" cultivar. The average fruit weight after storage decreased by $0.42 \mathrm{~g}$, which is $13.5 \%$ of the original fruit weight. Large losses in mass were also observed for the "Aurora" and "Darrow" cultivars. After the storage period, the average weight of the "Aurora" fruit is $1.85 \mathrm{~g}$, which means a weight decrease of $0.38 \mathrm{~g}$, and for the "Darrow" cultivar $-0.36 \mathrm{~g}$. The weight of the "Brigitta" cultivar has decreased from $1.8 \mathrm{~g}$ to $1.49 \mathrm{~g}$, and the "Elliott" cultivars from $1.62 \mathrm{~g}$ to $1.54 \mathrm{~g}$. The "Bluecrop" cultivar is characterized by low weight loss, the research shows that the size of the test factor decreased by $0.08 \mathrm{~g}$. Among all tested cultivars, the smallest weight loss was observed in the Duke cultivar. The difference between the average weight after harvest and the average weight after storage is only $0.02 \mathrm{~g}$.

In the next stage of the research, the geometrical characteristics of fruits were determined (Fig. 2). The height and diameter of the "Aurora" cultivar is respectively, on average, $12.18 \mathrm{~mm}$ and $16.93 \mathrm{~mm}$. For the "Brigitta" cultivar, the average fruit height is $12.21 \mathrm{~mm}$ and the diameter is $15.35 \mathrm{~mm}$. The obtained results show that the smallest fruits are found in the "Liberty" cultivar (average height $10.81 \mathrm{~mm}$, diameter $-14.95 \mathrm{~mm}$ ). Berries of the "Chandler" cultivar reach a height of $13.11 \mathrm{~mm}$ and a diameter of $19.46 \mathrm{~mm}$. The results for the "Elliott" cultivar are respectively $11.34 \mathrm{~mm}$ high and $15.33 \mathrm{~mm}$ in diameter, while the cultivars "Bluecrop" are $12.20 \mathrm{~mm}$ and $15.75 \mathrm{~mm}$. The "Duke" cultivar is characterized by an average height of $11.87 \mathrm{~mm}$ and a diameter of $15.36 \mathrm{~mm}$. The last of the analyzed cultivars - "Darrow" reaches a height of $13.54 \mathrm{~mm}$ and a diameter of $20.17 \mathrm{~mm}$. The results of the measurements show that this cultivar achieves the largest fruit size.

In the case of each of the cultivars studied, a loss of height and average values were noted after the storage period. This is most likely caused by water loss resulting in fruits shrinking. As it results from the measurements made, the highest average height and diameter was recorded for the "Darrow" cultivar - it is $12.43 \mathrm{~mm}$ and $19.35 \mathrm{~mm}$ respectively. The "Liberty" cultivar has the lowest height (it is $9.87 \mathrm{~mm}$ ), while the smallest diameter was recorded for the "Brigitta" cultivar $-14.43 \mathrm{~mm}$. In the case of the "Chandler" cultivar the biggest change in height occurred, the average height decreased by 1.16 $\mathrm{mm}$. Comparable changes were observed in the "Darrow" and "Brigitta" cultivars, where the value decreased by $1.11 \mathrm{~mm}$ and $1.00 \mathrm{~mm}$. In the slightest degree, the height decreased in the "Elliott" 
cultivar, decreased by $0.65 \mathrm{~mm}$ and reached $10.68 \mathrm{~mm}$. The average fruit height for the "Duke" cultivar is $11.12 \mathrm{~mm}$, for "Bluecrop" $11.53 \mathrm{~mm}$, and for blueberry "Aurora" $11.37 \mathrm{~mm}$. The biggest change in diameter was recorded for the "Brigitta" and "Chandler" cultivars, where the value drop reached approximately $0.93 \mathrm{~mm}$. In the case of the "Duke" variant, the diameter decreased slightly.

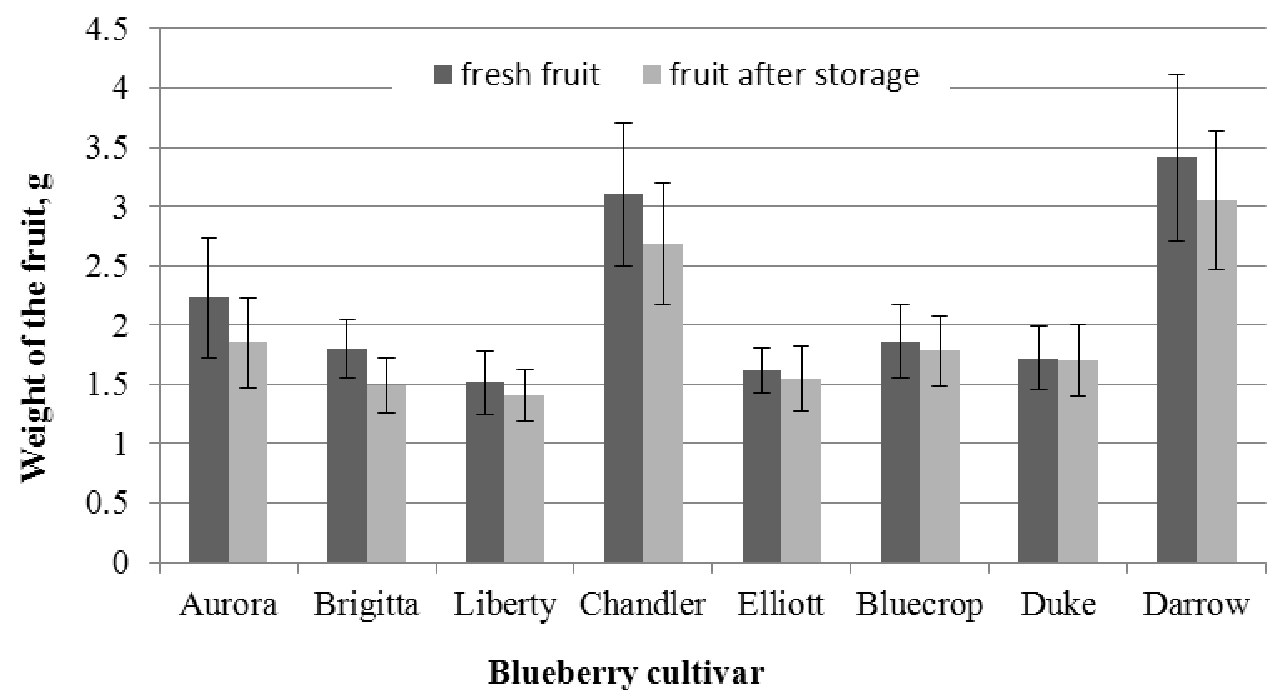

Fig. 1. Weight of tested fruit

Figure 3 presents the results of the tests of blueberry firmness measurement. The average value of the force needed to damage the "Aurora" cultivar fruit is $14.59 \mathrm{~N}$, while for the "Brigitta" cultivar it is only $7.45 \mathrm{~N}$. Higher strength was used for "Liberty" blueberry fruit $(16.35 \mathrm{~N})$, and the highest for fruit cultivar "Chandler" - $16.83 \mathrm{~N}$. The lowest value of force was observed during testing of "Duke" fruit (only $6.70 \mathrm{~N}$ ). Analyzing the obtained results it can be stated that "Chandler" and "Liberty" cultivars have fruits with the highest firmness, while the cultivars of "Bluecrop" and "Duke" have the smallest ones.

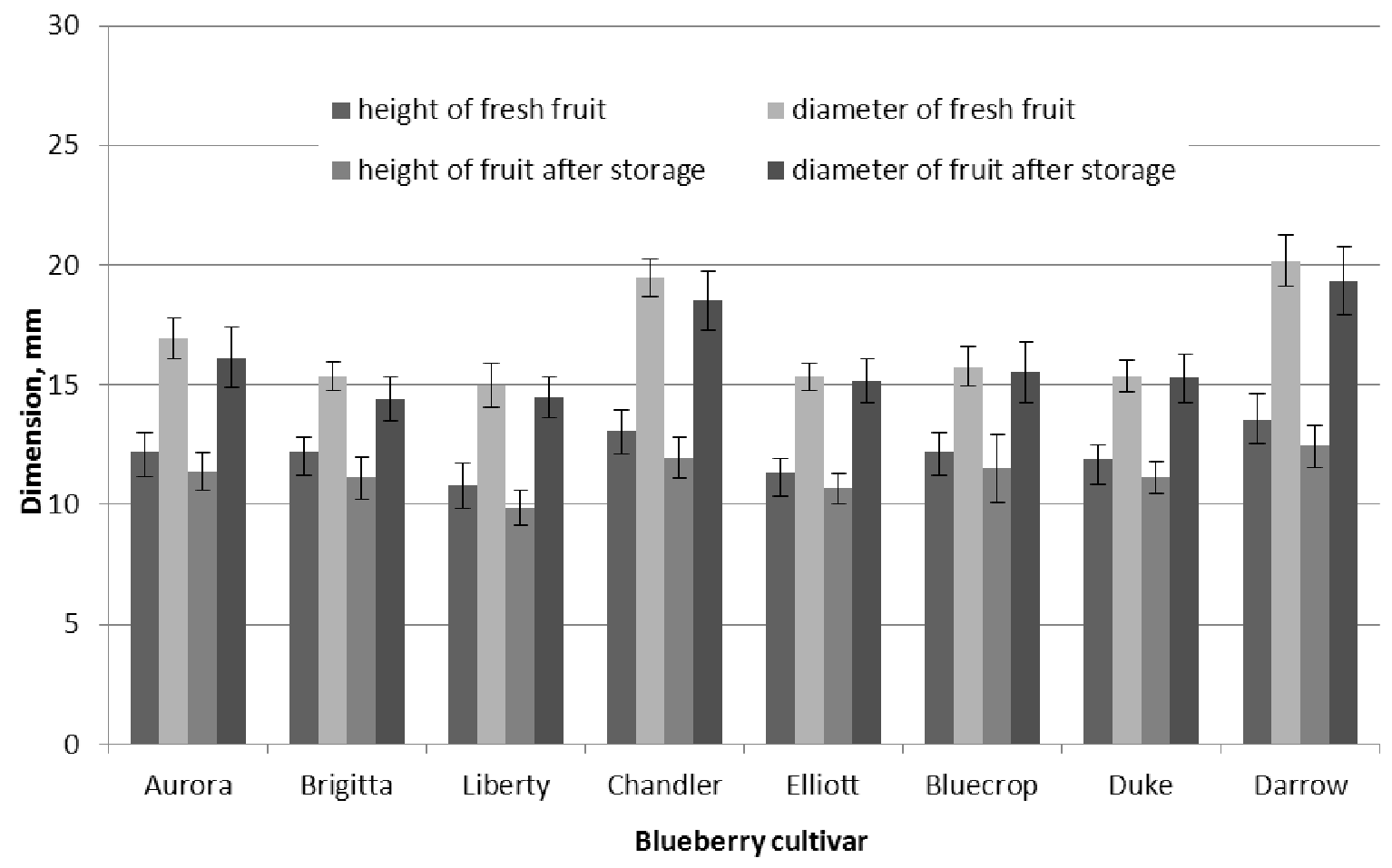

Fig. 2. Geometric dimensions of investigated fruits 
After the storage period, for seven of the cultivars studied, i.e. "Aurora", "Brigitta", "Liberty", "Chandler", "Eliot", "Bluecrop" and "Duke", there was an increase in the force necessary to crush the sample. The increase in firmness is probably caused by the drying of the skin of the fruit due to transpiration. According to the research, the highest average force was used during the squeezing of the "Liberty" cultivar fruit (19.03 N - increase in the force used to crush the sample of $2.76 \mathrm{~N})$. The lowest force was used to crush "Brigitta" fruit $(9.14 \mathrm{~N})$, with increase in the compression force by 1.69 $\mathrm{N}$. The greatest changes in fruit firmness after storage were observed in the "Elliott" cultivar, for which the average force necessary to crush the sample increased by $3.65 \mathrm{~N}$. An equally high increase in firmness was observed in the cultivars "Bluecrop" and "Duke". In the case of these cultivars, the average strength increased by $3.56 \mathrm{~N}$ and $2.80 \mathrm{~N}$ respectively. The obtained results show that the smallest difference occurs in the "Chandler" cultivar, the force necessary to destroy the sample increased by $0.72 \mathrm{~N}$. The "Darrow" cultivar is the only one among the tested cultivars characterized by decrease in firmness after storage. The average value of the force used to crush the sample is $11.73 \mathrm{~N}$, which means a reduction in the force by $1.13 \mathrm{~N}$.

The results of the sugar content tests are shown in the graph (Fig. 4). The average sugar content for the "Aurora" and "Liberty" cultivar is equal to $12.3^{\circ} \mathrm{Bx}$. In contrast, "Duke" recorded a value of $11.4^{\circ} \mathrm{Bx}$. Based on the results of the study, we can determine that the average sugar content for the "Brigitta" cultivar is $13.7^{\circ} \mathrm{Bx}$, for the "Chandler" $12.0^{\circ} \mathrm{Bx}$ cultivar, and for the "Elliott" $12,8^{\circ} \mathrm{Bx}$ cultivar. The "Bluecrop" cultivar has the highest average sugar content of $14.3^{\circ} \mathrm{Bx}$. The lowest sugar content was noted for the "Darrow" cultivar and is $10.6^{\circ} \mathrm{Bx}$. Analyzing the results of the research it can be concluded that the fruits of the "Bluecrop" and "Brigitta" cultivars are the sweetest. The difference between the cultivar with the largest and the smallest average sugar content is $3.7^{\circ} \mathrm{Bx}$

The average sugar content for all cultivars increased after storage. This is due to the ripening of the fruit. The largest average sugar content was recorded for the "Bluecrop" cultivar and it is $15.5^{\circ} \mathrm{Bx}$ and it increased by $1.3^{\circ} \mathrm{Bx}$. The lowest sugar content was measured in the "Chandler" cultivar, equal to $12.1^{\circ} \mathrm{Bx}$. The largest increase in the sugar content occurred in the "Duke" cultivar (increase by $2.6^{\circ} \mathrm{Bx}$ ). Mean growth was also observed in the "Darrow" cultivar, where the average sugar content increased by $2.2^{\circ} \mathrm{Bx}$ and reached the value of $12.8^{\circ} \mathrm{Bx}$. For the "Chandler" and "Aurora" cultivars, the results show a small increase of only $0.1^{\circ} \mathrm{Bx}$. For the "Brigitta" cultivar, the average sugar content after the storage period is $14.7^{\circ} \mathrm{Bx}$, for "Liberty" $13.2^{\circ} \mathrm{Bx}$, and for "Elliott" $13.0^{\circ} \mathrm{Bx}$.

The average sugar content for all cultivars increased after storage. This is due to the ripening of fruits in the cold store. However, differences in the sugar content in individual cultivars may result from several factors. Genetic differences, different levels of maturity during the harvest and the intensity of breathing processes during storage can be taken into account. As it is commonly known, the intensity of the process of fruit breathing in the storage room depends on the composition of the atmosphere and, in particular, the oxygen content. It consists of the breakdown of sugars into simple sugars and $\mathrm{CO}_{2}$ and this process is accompanied by heat release.

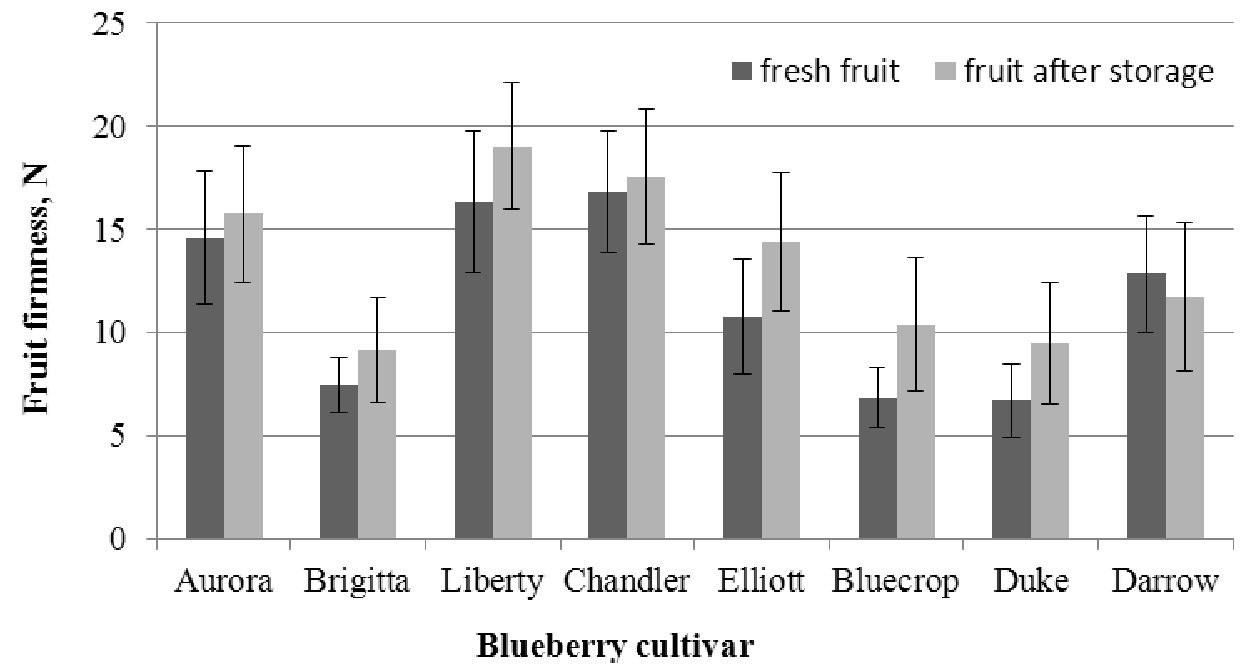

Fig. 3. Firmness of investigated blueberry fruits 


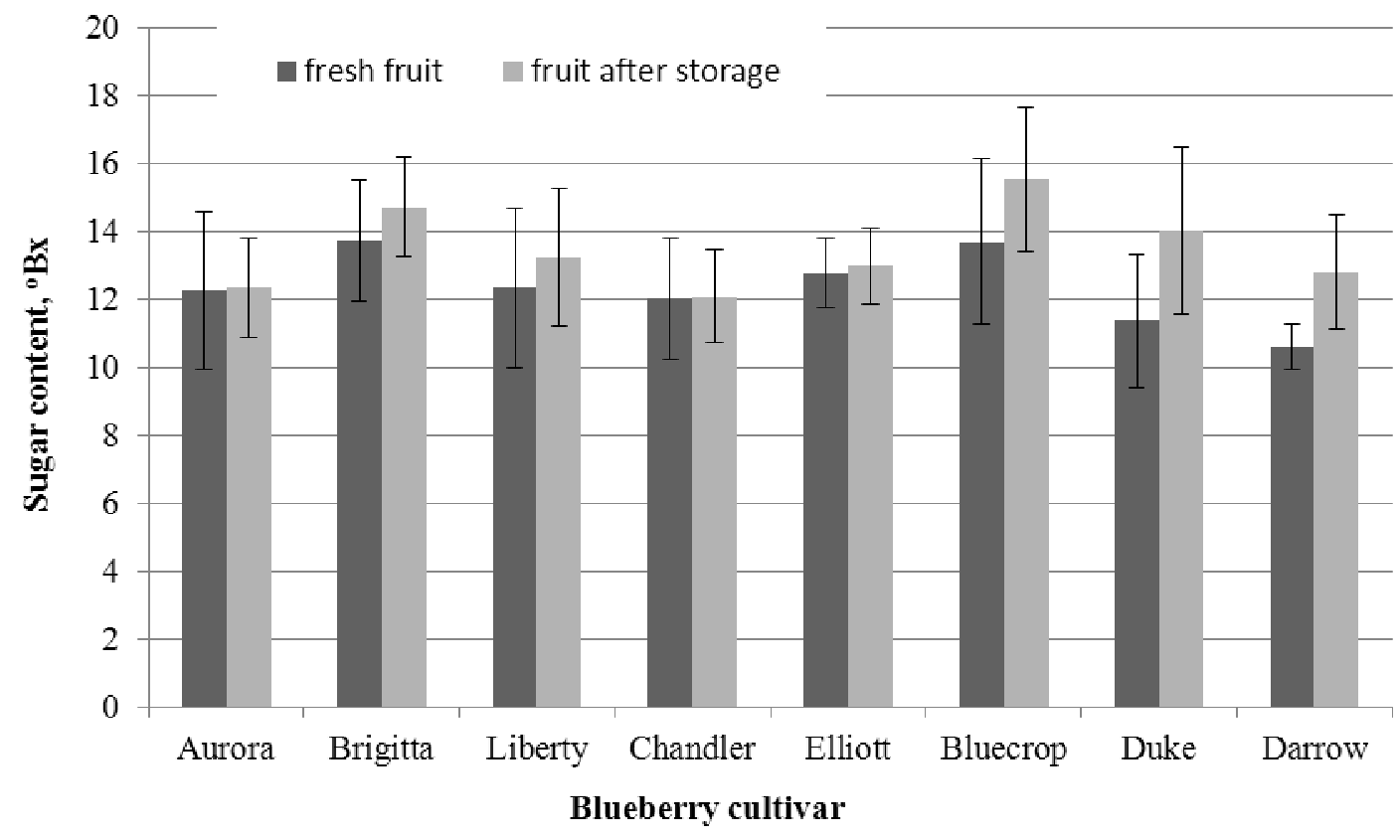

Fig. 4. Sugar content in tested fruits

The results were subjected to statistical analysis. An analysis of variance was performed using the Levene's test, taking into account significant differences, if $p \leq 0.05$. A multiple Duncan stretch test was also performed.

The analysis of the results was performed by performing multifactor tests of variance analysis for the data obtained during the research (Table 1). The independent variables in the tests were: term, mass, height, diameter, sugar and firmness. The analysis of variance in the table below showed the importance of all factors, except mass.

The next stage of the work was to perform statistical calculations. They consisted of carrying out the Duncan's test. The main factors taken into account were: the mass, height, diameter, firmness and the sugar content. The table below (Table 2) presents the results of statistical calculations for individual main factors and the date of the study. No homogeneous groups were observed for all the investigated factors. This indicates the existence of statistically significant differences in the mass, diameter, height, firmness and the sugar content of the tested samples between the test dates.

Table 1

One-dimensional significance tests for obtained test results

\begin{tabular}{|c|c|c|c|c|}
\hline Variable & $\begin{array}{c}\text { Average } \\
\text { square effect }\end{array}$ & $\begin{array}{c}\text { Mean } \\
\text { squared error }\end{array}$ & $\boldsymbol{F}$ & The $\boldsymbol{p}$-value \\
\hline Weight of the fruit & 0.34494 & 0.050845 & 6.784208 & 0.000002 \\
\hline Height of the fruit & 0.43111 & 0.411187 & 1.048455 & 0.403993 \\
\hline Diameter of the fruit & 1.12160 & 0.376064 & 2.982473 & 0.007575 \\
\hline Sugar content & 3.16211 & 1.145121 & 2.761378 & 0.012355 \\
\hline Fruit firmness & 12.76367 & 5.087195 & 2.509020 & 0.021517 \\
\hline
\end{tabular}

Duncan's test results for main factors

\begin{tabular}{|c|c|c|c|c|c|}
\hline $\begin{array}{c}\text { Research } \\
\text { number }\end{array}$ & $\begin{array}{c}\text { Weight of the } \\
\text { fruit }\end{array}$ & $\begin{array}{c}\text { Height of the } \\
\text { fruit }\end{array}$ & $\begin{array}{c}\text { Diameter of } \\
\text { the fruit }\end{array}$ & $\begin{array}{c}\text { Sugar } \\
\text { content }\end{array}$ & $\begin{array}{c}\text { Fruit } \\
\text { firmness }\end{array}$ \\
\hline first & A & A & A & A & A \\
\hline second & B & B & B & B & B \\
\hline
\end{tabular}




\section{Conclusions}

After storage, the firmness of all cultivars, except for the "Darrow" cultivar, has increased. This is due to the loss of water due to transpiration. The "Liberty" cultivar after 21 days from the harvest was characterized by the highest firmness, whereas the "Brigitt's" cultivar, the smallest. The "Darrow" cultivar is the only one with a decrease in firmness after storage, which indicates lower storage resistance.

The analysis of the conducted research allows to make the following conclusions:

1. lowering the storage temperature to $3{ }^{\circ} \mathrm{C}$ slows the biological processes leading to the maturation and overgrowth of blueberry fruits in a statistically significant way;

2. along with the increase in the storage period, the weight and size of the fruit for all tested cultivars decreases and the characteristic wrinkles appear on the berries. This is a result of the loss of water in the fruit due to breathing;

3. with the passage of time since the harvest, the sugar content in the tested cultivars increases, which is the result of fruit ripening;

4. it is necessary to conduct further research aimed at finding the optimal storage time for blueberry fruit for increasing the sugar content in them without significantly losing their quality (firmness).

\section{Acknowledgments} Poland

This research was financed by the Ministry of Science and Higher Education of the Republic of

\section{References}

[1] Chiabrando V., Giacalone G., Rolle L. Mechanical behaviour and quality traits of highbush blueberry during postharvest storage. Journal of the Science of Food and Agriculture. vol. 89. no. 6, 2009, pp. 989-992.

[2] Sinelli N., Spinardi A., Di Egidio V., Mignani I., Casiraghi E. Evaluation of quality and nutraceutical content of blueberries (Vaccinium corymbosum L.) by near and mid-infrared spectroscopy. Postharvest Biology and Technology. vol. 50. no. 1. 2008, pp. 31-36.

[3] Antonio G., Faria F., Takeiti C., Park K. Rheological behovior of blueberry. Ciencia y Tecnologia de Alimentos. vol. 29, 2009, pp. 732-737.

[4] Krupa T., Tomala K., Effects of storage condition on anthocyanin content and antioxidative activity in highbush blueberries fruit. Food. Science. Technology. Quality. 2006. 2 (47) Supl., pp. 171-181

[5] Cortés-Rojas M. E., Mesa-Torres P. A., Grijalba-Rativa C. M., Pérez-Trujillo M. M. Yield and fruit quality of the blueberry cultivars Biloxi and Sharpblue in Guasca. Colombia. Agronomía Colombiana 34(1). 2016, pp. 33-41

[6] Duarte C., Guerra M., Daniel P., Camelo A. L., Yommi A., Quality changes of highbush blueberries fruit stored in CA with different $\mathrm{CO}_{2}$ levels. Journal of Food Science. vol. 74. no. 4, 2009, pp. 154-159.

[7] Smolarz K. Blueberry and cranberry - the principles of rational production. Warsaw. 2009. Publishing Hortpress.

[8] Moura G., Vizzotto M., Picolotto L., Antunes L. E. C. Production. physical-chemical quality and bioative compounds of misty blueberry fruit under different pruning intensities. Rev. Bras. Frutic.[online]. 2018. vol.39. n.spe. e-158. Epub Feb 09. 2017. ISSN 0100-2945. http://dx.doi.org/10.1590/0100-29452017158.

[9] Nunes M. C., Emon J. P., Brecht J. K. Quality curves for Highbush blueberries as a function of the storage temperature. Proceedings of the 9th North American Blueberry Research and Extension Workers Conference; and In Small Fruits Review. Food Product press. Haworth Press. 2004, pp. 423-438.

[10] Matiacevich S., Cofré D.C., Silva P., Enrione J., Osorio F. Quality Parameters of Six Cultivars of Blueberry Using Computer Vision. International Journal of Food Science Volume 2013. Article ID 419535. 